\title{
Juventude, direitos humanos e inclusáo social: um projeto dedicado aos jovens
}

Youth, human rights and social inclusion: a project dedicated to young people

\section{RESUMO}

Este artigo avalia a experiência com jovens desenvolvida pelo projeto de extensão intitulado "Juventude, Direitos Humanos e Inclusão Social da Universidade Regional de Blumenau (FURB)". O projeto conta com a participação de graduandos e docentes dos cursos de História e Serviço Social no intuito de utilizar os conhecimentos acadêmicos de distintas áreas para melhores açôes voltadas para a sociedade. $\mathrm{O}$ objetivo principal consiste na promoção dos Direitos Humanos e da inclusão social entre jovens, incentivando o seu exercício pró-ativo nos espaços decisórios na arena municipal. No decorrer de 2017, a metodologia utilizou diferentes açóes, tais como: reunióes, oficinas e elaboração de folder e vídeos. Os temas tratados com a juventude focalizaram os Direitos Humanos, em especial o direito à vida e sua contextualização, bem como o Estatuto da Juventude. A extensão proporciona aos seus participantes a oportunidade de diálogo com os jovens, maximizando os conhecimentos teóricos aprendidos na academia e dando um retorno social das práticas da universidade.

Palavras-chave: Juventude. Direitos humanos. Inclusão social.
Juliana de Mello Moraes

Pós-doutora em História pela Universidade Federal do Paraná, Brasil, e pela Universidade de Lisboa, Portugal, com bolsa da Fundaçáo para a Ciência e a Tecnologia (FCT-Portugal); professora na Universidade Regional de Blumenau, Santa Catarina, Brasil(jmmoraes@ furb.br).

Cleide Gessele

Doutora em Serviço Social pela Universidade Federal de Santa Catarina, Brasil; professora na Universidade Regional de Blumenau, Santa Catarina, Brasil (cleidege@yahoo.com.br).

Petra Beatrice Lickfeld

Graduanda em Serviço Social na Universidade Regional de Blumenau, Santa Catarina, Brasil; bolsista de extensão no projeto "Juventude, Direitos Humanos e Inclusão Social na FURB" (petrab.lickfeld@hotmail.com).

Hiago de Souza

Graduando em História na Universidade Regional de Blumenau, Santa Catarina, Brasil; bolsista de extensáo no projeto "Juventude, Direitos Humanos e Inclusão Social na FURB” (hiagodesouza2@ gmail.com)(hiagodesouza2@gmail. com).

\begin{abstract}
This article evaluates the experience with young people developed by the extension project titled "Youth, Human Rights and Social Inclusion of the Regional University of Blumenau (FURB), State of Santa Catarina, Brazil. It counts on the participation of History and Social Service's undergraduates and teachers in order to use the academic knowledge of different areas for better actions aimed at society. The main objective is to promote human rights and social inclusion among young people, encouraging their proactive exercise in decision-making spaces in the municipal arena. During the course of 2017, the methodology used different actions, such as: meetings, workshops and folder elaboration. The issues addressed with youths focused on human rights, in particular the right to life
\end{abstract}


and its contextualization, as well as the Youth Statute. Extension gives its participants the opportunity to dialogue with young people, maximizing the theoretical knowledge learned in the academy and giving a social return of university practices.

Keywords: Youth. Human rights. Social inclusion.

\section{INTRODUÇÃO}

Este artigo avalia a experiência do projeto de extensão "Juventude, Direitos Humanos e Inclusão Social, extensão dos Departamentos de História e Serviço Social da Universidade Regional de Blumenau (FURB)", realizado com os jovens matriculados no segundo ano da Escola de Ensino Médio Elza Pacheco no município de Blumenau, Santa Catarina. O intuito do referido projeto consiste em dialogar com os jovens e a população sobre os desafios de ser jovem em uma sociedade complexa, contraditória e, principalmente, táo desigual. Paralelamente, pretende-se, a partir da articulação entre direitos humanos e direitos da juventude, estimular a participaçấo ativa e democrática dos jovens na sua comunidade, bem como na cidade de Blumenau.

A valorização do espaço escolar como lócus privilegiado para a promoção dos Direitos Humanos ampliou-se a partir de 2005, quando a Organização das Naçóes Unidas para a Educação, a Ciência e a Cultura (Unesco) divulgou o Programa Mundial para Educação em Direitos Humanos, o qual orientava e definia diretrizes para a efetivação dessa temática na educação (SILVA, 2010, p. 42). Além disso, atualmente a Base Nacional Comum Curricular, homologada em dezembro de 2017, também destaca entre as competências gerais para a educação básica a necessidade dos estudantes saberem se posicionar e tomar decisóes pautadas nos Direitos Humanos.

Nesse sentido, partimos do pressuposto que a consciência universal dos Direitos Humanos é cada vez mais forte no contexto contemporâneo, sendo sua valorização e promoção essencial entre os jovens, uma vez que contribui para o fortalecimento da democracia, da igualdade e da tolerância. É oportuno destacar que em sociedades marcadas pela exclusão, pelos conflitos, pelas desigualdades estruturais e pelas situaçóes de injustiça institucionalizada, a questáo dos Direitos 
Humanos se torna central e urgente.

Os debates sobre os Direitos Humanos no Brasil ocorreram ao longo das décadas de 1970 e 1980, no contexto de luta pelos direitos civis e políticos. O envolvimento de distintos movimentos sociais na contestação da ditadura e na situação de desigualdade marcou o processo de estabelecimento dos Direitos Humanos no país. Nesse cenário, as instituiçôes de educação superior também participaram da difusão e promoção de tais direitos, por meio de açôes diversas, incluindo mais recentemente aquelas de extensão e pesquisa. Desse modo, a efetivação de práticas relacionadas aos Direitos Humanos nas universidades públicas não ocorreu inicialmente por uma lei ou decreto, pois,

Os direitos humanos entraram na universidade a partir de experiências concretas de educação popular nos anos 1960, de resistências e lutas nos anos 1970 e de institucionalização dos direitos humanos na extensão universitária nos anos 1980, com o processo de democratização, avançando nos anos 1990 no Ensino, na Pesquisa e na Gestão. (ZENAIDE, 2010, p. 69).

Embora seja temática relevante nas açóes das instituiçóes de ensino superior, o recente desenvolvimento de atividades relacionadas à temática nas universidades indica a importância em expandir a implantaçáo e promoção da educaçáo em Direitos Humanos e de fomentar a extensão nessa área. Inicialmente, os projetos de extensão em Direitos Humanos atendiam e ainda contemplavam algumas demandas específicas vinculadas à questão da terra, dos povos indígenas, das populaçóes de localidades isoladas ou ribeirinhas e no combate à violência institucional (ZENAIDE, 2010, p. 73). Entretanto, as mudanças dos últimos anos exigiram a atenção aos novos contextos e desafios, emergindo temáticas como o meio ambiente, as tecnologias e as relaçôes internacionais.

Dentre as matérias de destaque encontram-se também o reconhecimento da juventude e das suas especificidades em relaçáo a crianças e adultos, pois essa perspectiva tem ganhado relevância em diferentes espaços, 
como no meio acadêmico ou nas mídias, bem como nas agendas governamentais e não governamentais, os jovens têm angariado visibilidade. Nos meios de comunicação, por exemplo, os jovens aparecem ora vítimas da violência, ora protagonistas de problemas sociais, desemprego, drogas, gravidez precoce, dentre outros (NOVAES, 2007). Já nas ações do Estado, os jovens receberam relevo a partir de meados da década de 1990 com as primeiras políticas direcionadas à juventude. Entretanto, o jovem "como sujeito de direitos, visto como responsável pelo desenvolvimento da sociedade, e não como problema, tornou-se um tema que teve como ápice e ponto de partida os anos de 2003, 2004 e 2005” (SEVERO, 2014, p. 6).

As distintas aproximações à temática refletem as formas de perceber e compreender os jovens na contemporaneidade, porém ainda subsistem algumas representaçóes alicerçadas em estereótipos baseados no senso comum ou numa visão maniqueísta da juventude.

Atualmente, em Blumenau, dados de pesquisa desenvolvida com professores do Ensino Médio da Escola de Educação Básica Prof. João Widemann demonstraram que as representaçôes da juventude entre esse grupo indicam três tendências (MORAES, 2013). A primeira representação adotada pelos sujeitos da pesquisa relaciona a juventude com uma "fase de vida". A segunda tendência a percebe como "estado de espírito", enquanto a terceira relaciona "fase de vida" a um "estado de espírito". No que se refere às expectativas dos professores sobre os jovens, verifica-se uma percepção sobre a capacidade de propor o novo, de ser destemida, participativa, revolucionária. Entretanto, o estudo revela também a presença de sentimento de frustração, o qual compreende a juventude como conservadora, individualista, rebelde, inerte e relapsa. Tais expectativas orientam as práticas direcionadas à juventude que se mostram ambivalentes, podendo se materializar em ações voltadas para o investimento no desenvolvimento do potencial desses sujeitos ou, ao contrário, na precariedade do investimento justificada pela crença na incapacidade dos jovens.

Desse modo, qualquer ação destinada à juventude deve se afastar dessas representaçóes que permanecem no imaginário, incluindo dos próprios professores, uma vez que "os jovens de hoje certamente não são os jovens do passado, tampouco os jovens do futuro. Entretanto, uma coisa eles têm em comum: são sujeitos históricos, culturais, 
sociais e localizados em um determinado lugar" (CAVALCANTE, 2014, p. 47). Nesse sentido, o conceito de juventude se relaciona às dinâmicas sociais e históricas, variando seu significado de acordo com os contextos e tempo. Além disso, é necessário agregar-lhe a multiplicidade de representaçóes e construçóes sociais sobre o universo juvenil no presente (ALVES, 2013). Finalmente, destaca-se que tal conceito deve englobar, ainda, outras características referentes à juventude, tais como gênero, grupo social, raça, vínculos familiares e religiosos. Esses contribuem para a sua multiplicidade e complexidade, uma vez que nem todos os jovens partilham as mesmas experiências.

A miríade de realidades no universo juvenil permite relativizar perspectivas elaboradas, sobretudo a partir de 1968, as quais associam a juventude ao ímpeto revolucionário e transformador (MONDAINI, 2013). Logo, para compreender a relação entre juventude, Direitos Humanos e inclusão social é necessário considerar a pluralidade, as clivagens e a complexidade desse grupo. Assim, a juventude como categoria social complexa possui sua própria dinâmica histórica, devendo ser apreendida na sua pluralidade e nos seus distintos modos, no intuito de evitar estereótipos que reforçam preconceitos.

No âmbito governamental, tal como anteriormente referido, as discussóes acerca dos direitos da juventude ocorreram principalmente a partir de 2003. Os debates geraram diferentes repercussóes e originaram instituiçóes dedicadas exclusivamente aos jovens como a Secretaria Nacional da Juventude e o Conselho Nacional da Juventude, ampliando os espaços de representação dos jovens na arena federal. Além disso, foram estabelecidas políticas para atender demandas de inclusão dos jovens no mercado de trabalho (Primeiro Emprego). Contudo, essas açóes ocorreram de forma dispersa e desarticulada, não configurando um conjunto coeso de promoção da condição dos jovens tendo em conta os diferentes contextos e pluralidade socioeconômica da juventude brasileira.

No entanto, o reconhecimento do jovem como sujeito de direitos ocorreu somente sete anos após o início dessas iniciativas, pois

a PEC da Juventude, aprovada em julho de 2010, é um marco legal e político que coloca a discriminação, a violência ou opressáo contra os jovens 
sob responsabilidade constitucional. A partir desse momento, solidificam-se os direitos particulares da juventude. A Proposta de Emenda à Constituição da Juventude possibilitou incluir os jovens como sujeitos de direitos no Artigo 227 da Constituiçãao Federal. (SEVERO, 2014, p. 5).

A partir da PEC da Juventude, os jovens foram reconhecidos nas suas especificidades, o que facilitou, a partir desse momento, a elaboração de políticas públicas e programas destinados especialmente à juventude. Paralelamente, é fundamental referir que o reconhecimento dos jovens na Constituição de 1988 proporcionou igualmente a aprovação de legislação dedicada a esse grupo. Nesse sentido, após a aprovação da PEC, a proposta na Câmara dos Deputados do projeto do Estatuto da Juventude discutido desde 2005 e destinado a valorizar e promover a inclusão social da juventude do país recebeu novo impulso.

Entretanto, a legislação dedicada exclusivamente à juventude ocorreu somente após inúmeros debates na esfera política, em agosto de 2013, através da Lei no 12.852, a qual instituiu o Estatuto da Juventude. Esse documento dispóe sobre os direitos dos jovens, os princípios e as diretrizes das políticas públicas destinadas a esse público (BRASIL, 2013).

Segundo o Art. $1^{\circ}$, são consideradas jovens as pessoas com idade entre 15 (quinze) e 29 (vinte e nove) anos de idade. Enquanto os princípios das políticas públicas voltadas para a juventude, de acordo com o Art. $2^{\circ}$ do Estatuto da Juventude, são os seguintes: I - promoção da autonomia e emancipação dos jovens; II - valorização e promoção da participação social e política, de forma direta e por meio de suas representaçôes; III - promoção da criatividade e da participação no desenvolvimento do País; IV - reconhecimento do jovem como sujeito de direitos universais, geracionais e singulares; $\mathrm{V}$ - promoção do bem-estar, da experimentação e do desenvolvimento integral do jovem; VI - respeito à identidade e à diversidade individual e coletiva da juventude; VII - promoção da vida segura, da cultura da paz, da solidariedade e da não discriminação; e VIII - valorização do diálogo e convívio do jovem com as demais gerações (BRASIL, 2013). 
A partir desse documento, atesta-se a necessidade de promover entre os jovens os Direitos Humanos, relacionando-os com a valorizaçáo da participação em distintas organizaçôes juvenis. Esse diploma legal reconhece os jovens do país ao possibilitar e incentivar o pleno exercício de sua cidadania, pois, nesse documento, o jovem não é compreendido como um ser frágil e incapaz de tomar as rédeas de sua vida, mas sim como um ser autônomo, construtor da sociedade e que deve discutir, formular e executar políticas de juventude no Brasil.

Entretanto, essa participação presume uma vivência com sentidos e significados para aqueles que desenvolvem as açôes (NOGUEIRA, 2011apud GOHN, 2008), sendo necessário que os jovens estejam inseridos em práticas de significaçóes condizentes com a criação de processos identitários individuais e coletivos, desenvolvendo a efetiva conquista da autonomia. O conhecimento tanto da legislação quanto do documento fundamental dos Direitos Humanos propicia aos jovens reconhecer, analisar e construir reflexôes críticas sobre sua própria condição e desta com seu contexto. Isso porque o reconhecimento dos jovens como sujeitos de direitos favorece sua capacidade de intervenção na sociedade.

Nesse sentido, valorizar a participação proativa, inclusive por meio de organizaçóes, e fomentar o exercício da cidadania implicam na promoçáo dos interesses coletivos de distintas naturezas, pautados antes de mais na democracia e na valorização da justiça social, ou seja, nos Direitos Humanos. Assim, torna-se essencial desenvolver açôes que despertem o interesse dos jovens pelos espaços políticos e decisórios na perspectiva de enfrentar desde demandas locais como a luta por interesses mais gerais da sociedade e pela efetiva participaçáo na gestão da cidade. A mobilização dos jovens no esforço pela ampliaçáo de direitos e do acesso às políticas sociais (melhoria de acessibilidade, transporte, áreas de lazer, saúde, assistência social, centro de educaçáo infantil, entre outros) emergem como questóes centrais na atualidade.

A partir dos pressupostos acima, foram definidos os objetivos do projeto de extensão, sendo respectivamente: contribuir para a promoção dos Direitos Humanos e da inclusão social entre os jovens, incentivando o seu exercício proativo nos espaços decisórios na arena municipal; estimular por meio de diálogos uma reflexão crítica a 
respeito dos Direitos Humanos; conhecer e discutir o Estatuto da Juventude; fomentar a articulação entre ensino, pesquisa e extensão; incentivar a participaçáo dos jovens nos espaços de representaçáo política da juventude; e, finalmente, debater sobre as relaçôes entre Direitos Humanos, inclusão social e promoção dos direitos da juventude.

O projeto é composto por um grupo multidisciplinar, incluindo Serviço Social e História, o que favorece a integraçáo de diferentes áreas de saber, ampliando as perspectivas de trabalho com os jovens, bem como da análise das atividades desenvolvidas ao longo da sua vigência. Compreende-se a realização da extensão como um caminhar coletivo e cooperativo, com interlocução entre profissionais, jovens e parceiros externos à Universidade, em busca de uma açáo cidadá para superar as situações de desigualdade e de exclusão existentes no Brasil. Nesse sentido, o projeto destaca a importância de "saldar a dívida com os jovens brasileiros, pois o Brasil foi um dos últimos países na América Latina a consolidar de forma integrada políticas públicas e direitos dos jovens" (SEVERO, 2015, p. 10).

A experiência adquirida com esse projeto permite avaliar tanto as atividades desenvolvidas durante seu primeiro ano de vigência, no intuito de rever ou alterar tais açôes, quanto os resultados obtidos com os jovens.

\section{Ações desenvolvidas com os jovens}

Para a viabilização da proposta do projeto foi realizada uma reunião com a direção da Escola de Ensino Médio Elza Pacheco, para apresentação do projeto, dos eixos e respectivos conteúdos, definição das turmas a participarem das atividades e cronograma de datas para execuçáo das oficinas.

Entre abril e novembro de 2017, foram ofertadas oito oficinas, de aproximadamente duas horas cada, com 70 estudantes. Os conteúdos abordados estấo dispostos no quadro abaixo: 
Quadro 1 - Atividades realizadas com os jovens

\begin{tabular}{|c|c|c|c|}
\hline Eixos & Oficinas & Objetivos & Datas \\
\hline \multirow{3}{*}{$\begin{array}{l}\text { Eixo 1: } \\
\text { Direitos } \\
\text { Humanos }\end{array}$} & $\begin{array}{l}\text { Oficina } 1: \text { Imagens } \\
\text { da vida }\end{array}$ & $\begin{array}{l}\text { Refletir sobre o que são } \\
\text { Direitos Humanos; } \\
\text { Possibilitar uma visão crítica } \\
\text { em relação à sociedade de } \\
\text { classe que determina as } \\
\text { condiçóes de vida das pessoas } \\
\text { e grupos sociais. }\end{array}$ & $05 / 04 / 2017$ \\
\hline & $\begin{array}{l}\text { Oficina 2: Direito } \\
\text { à vida em nossa } \\
\text { sociedade ontem } \\
\text { e hoje }\end{array}$ & $\begin{array}{l}\text { Refletir sobre os eventos } \\
\text { históricos que possibilitaram } \\
\text { a conformação dos Direitos } \\
\text { Humanos. }\end{array}$ & $08 / 05 / 2017$ \\
\hline & $\begin{array}{l}\text { Oficina 3: Direito } \\
\text { à vida: nosso } \\
\text { compromisso }\end{array}$ & $\begin{array}{l}\text { Conhecer e refletir sobre os } \\
\text { Direitos Humanos. } \\
\text { Refletir sobre o valor da vida, } \\
\text { como direito primordial e } \\
\text { básico de todas as pessoas e } \\
\text { grupos humanos. }\end{array}$ & $21 / 06 / 2017$ \\
\hline \multirow[b]{2}{*}{$\begin{array}{c}\text { Eixo 2: } \\
\text { Juventude }\end{array}$} & $\begin{array}{l}\text { Oficina 4: Estatuto } \\
\text { da Juve n t ude: } \\
\text { conhecer é preciso }\end{array}$ & $\begin{array}{l}\text { Apresentar o Estatuto da } \\
\text { Juventude refletindo sobre os } \\
\text { direitos da juventude e como } \\
\text { garanti-los. }\end{array}$ & $14 / 08 / 2017$ \\
\hline & $\begin{array}{l}\text { Oficina 5: } \\
\text { Conhecendo } \\
\text { o Conselho } \\
\text { Municipal da } \\
\text { Juventude de } \\
\text { Blumenau }\end{array}$ & $\begin{array}{l}\text { Conhecer o Conselho } \\
\text { Municipal da Juventude de } \\
\text { Blumenau com a presença } \\
\text { de dois conselheiros. }\end{array}$ & $28 / 08 / 2017$ \\
\hline
\end{tabular}




\begin{tabular}{|c|c|c|c|}
\hline \multirow{3}{*}{$\begin{array}{l}\text { Eixo 3: } \\
\text { Juventude, } \\
\text { Direitos } \\
\text { Humanos } \\
\text { e Inclusão } \\
\text { Social }\end{array}$} & $\begin{array}{l}\text { Oficina 6: } \\
\text { Juventude e seu } \\
\text { lugar na sociedade }\end{array}$ & $\begin{array}{l}\text { Selecionar um tema } \\
\text { relacionado às oficinas } \\
\text { anteriores e elaborar roteiro } \\
\text { com os jovens para produção } \\
\text { de vídeos. }\end{array}$ & $11 / 09 / 2017$ \\
\hline & $\begin{array}{l}\text { Oficina } 7: \\
\text { Produção dos } \\
\text { vídeos sobre } \\
\text { Juventude e seu } \\
\text { lugar na sociedade }\end{array}$ & $\begin{array}{l}\text { Exibir Vídeo 1: Liberdade } \\
\text { Exibir Vídeo 2: Direitos } \\
\text { Humanos } \\
\text { Exibir Vídeo 3: Livres \& } \\
\text { Iguais } \\
\text { Exibir Vídeo 4: Direitos } \\
\text { Humanos } \\
\text { Exibir Vídeo 5: Direitos } \\
\text { Humanos e a Escola }\end{array}$ & 23/10/2017 \\
\hline & $\begin{array}{ll}\text { Oficina } & 8: \\
\text { Avaliação } & \text { do } \\
\text { projeto } & \end{array}$ & $\begin{array}{l}\text { Avaliar com os jovens, } \\
\text { público do projeto de } \\
\text { extensão, sobre as açóes } \\
\text { desenvolvidas ao longo do } \\
\text { ano. }\end{array}$ & 07/11/2017 \\
\hline
\end{tabular}

Fonte: Arquivo do Projeto (2017).

No Eixo 1 - No Eixo 1 - Direitos Humanos, trabalhamos a primeira oficina com o tema denominado "Imagens da Vida", a qual contou com a exposiçáo dialogada a partir do uso de material visual. Para explorar os conteúdos teóricos, foram utilizadas 26 imagens que rompiam com o que os Direitos Humanos propóem. Tal recurso foi utilizado para expressar a violação desses direitos no mundo e no Brasil. Durante a exposição os grupos foram instigados a relacionar os conteúdos com a sua realidade, e, posteriormente os jovens socializaram suas opinióes sobre as referidas imagens. Essa atividade propiciou a análise crítica, reflexão e a elaboração de argumentos entre os estudantes a respeito da temática proposta. As socializaçóes evidenciaram o conhecimento de alguns direitos entre os jovens, mas igualmente algumas concepçóes equivocadas a respeito da História do país e seu recente processo de democratização. Também, proporcionou aos membros do projeto um diagnóstico dos conhecimentos prévios e do senso crítico dos estudantes.

Na oficina 2, denominada "Direito à vida em nossa sociedade ontem 
e hoje", contextualizou-se com os jovens a história dos Direitos Humanos. O conhecimento do percurso histórico e da conformação desses direitos são fundamentais, pois permite aos jovens compreender as dinâmicas envolvidas na sua concepção, bem como os processos de conquistas protagonizados pelas populaçóes em diferentes momentos da História.

Desse modo, inicialmente foram disponibilizadas informaçôes aos alunos sobre o contexto histórico dos seguintes documentos: Declaração Universal dos Diretos Humanos (1948), Constituição da República Federativa do Brasil (1988), Declaração de Direitos do Bom Povo de Virgínia (1776) e Declaração dos Direitos Inglesa (1689). É importante salientar que no conteúdo dos documentos utilizados se encontra a base para o reconhecimento dos Direitos Humanos. Partindo dos referidos contextos históricos, era tarefa dos estudantes realizar a montagem de uma linha do tempo, ordenando os acontecimentos de forma cronológica, com o intuito de perceberem que o processo que culminou na elaboração dos Direitos Humanos ocorreu em tempos de crise. Como salienta Mondaini (2009), é fundamental compreender que o terreno sobre o qual são erguidos os Direitos Humanos se apresenta como um verdadeiro campo de conflito, dando forma a uma luta em torno daquilo que deve ser observado como "legal" pelo Estado, mas também como "legítimo" pela sociedade.

Essa oficina objetivou agregar à compreensão dos jovens a relevância das mutaçóes sociais e as possibilidades de transformaçóes engendradas nas sociedades, ou seja, evidenciou a alteração e reconstrução de normas de convívio e dinâmicas sociais. A percepção dessas transformaçóes permite aos jovens conhecer e avaliar açóes proativas, estimulando sua própria atuação como cidadãos. Nesse sentido, a oficina baseouse nos conhecimentos prévios dos estudantes para a construção de uma linha do tempo baseada em momentos fundamentais para a construção dos Direitos Humanos, no intuito de proporcionar aos jovens a percepção das conexóes entre o nacional e o internacional na conformação desses direitos.

A terceira oficina, denominada "Direito à vida: nosso compromisso", teve como principal objetivo apresentar, discutir e fomentar a reflexão sobre os Direitos Humanos e seus princípios fundamentais 
para a conservação da vida. Foi exibido um vídeo sobre o tema, que abordava os 30 artigos da Declaração Universal de Direitos Humanos, relacionando-os a situaçôes cotidianas. Posteriormente, instigou-se que os estudantes apontassem quais direitos lhes havia despertado mais atenção. A socializaçáo das opinióes dos jovens fomentou o debate sobre o respeito à diversidade, ao direito à educação e a importância de se conhecer os Direitos Humanos. A partir desse diálogo foi possível detectar a relevância de se trabalhar com os jovens sobre o respeito mútuo, a compreensão e tolerância diante das diversidades.

Além dessa discussão, propomos aos jovens refletir sobre seu cotidiano e suas experiências, focalizando a necessidade de atendermos e promovermos os Direitos Humanos em nosso dia-a-dia. Para incentivar a reflexão foram distribuídos fôlderes, elaborados no âmbito do projeto, no intuito de reforçar a relevância dos Direitos Humanos e dos possíveis canais de informação, tal como websites e números telefônicos disponibilizados pelo Governo Federal, para denunciar abusos e situaçôes que desrespeitem esses direitos atualmente. Essa ação se enquadra na necessidade de difundir o conhecimento sobre os respectivos direitos entre a juventude e lhes facultar hipóteses de ação, conforme figuras 1 e 2 .

Figura 1 - Oficina 3: Direito à vida: nosso compromisso

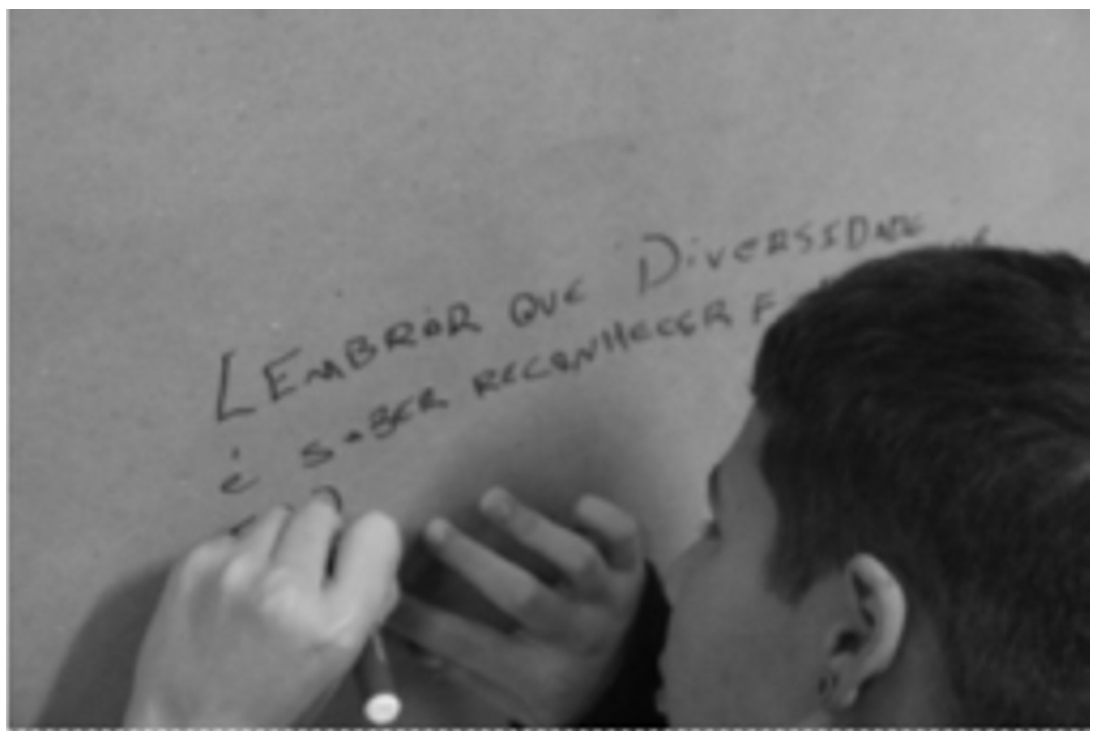

Fonte: Arquivo do Projeto (2017). 
Figura 2 - Oficina 3: Folder Direitos Humanos

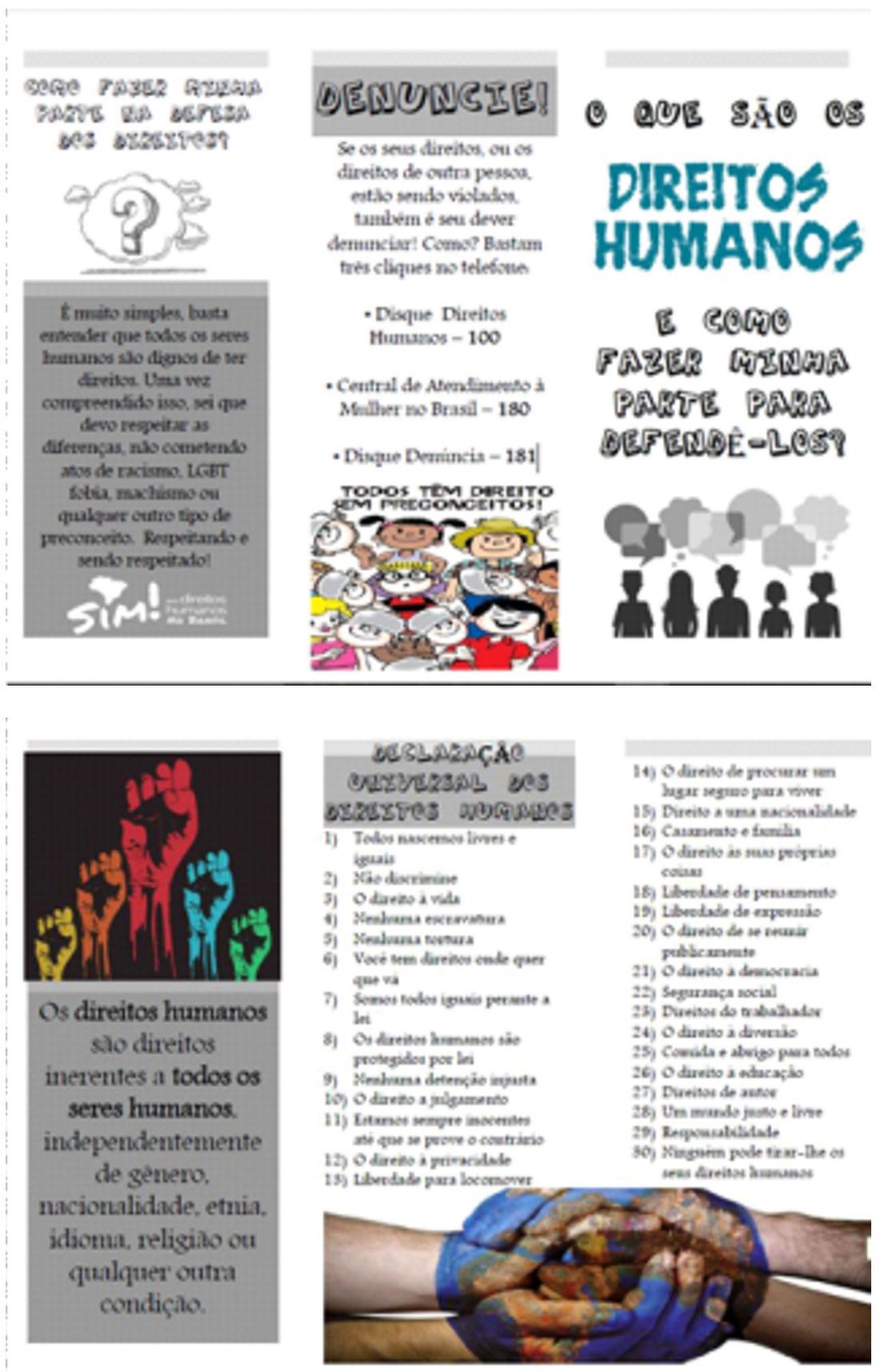

Fonte: Arquivo do Projeto (2017). 
A quarta oficina teve como propósito apresentar aos jovens o Estatuto da Juventude e estabelecer uma reflexão sobre esse documento. No início da oficina, verificamos que muitos jovens desconheciam tal documento. Em seguida, propusemos que os estudantes refletissem e indicassem o que consideravam fundamental constar em um estatuto da juventude, assim observamos que muitos dos direitos que eles citaram já existiam.

$\mathrm{Na}$ sequência da oficina, dialogamos sobre as organizaçóes da juventude, em especial sobre a União Brasileira de Estudantes Secundaristas (UBES) e a União Nacional dos Estudantes (UNE). Novamente, entregamos fôlderes contendo informaçôes sobre essas instituiçóes e sua relevância para a defesa dos direitos dos jovens no país.

$\mathrm{Na}$ quinta oficina, possibilitamos aos jovens do projeto uma aproximaçáo com dois conselheiros municipais da juventude de Blumenau. $\mathrm{Na}$ oficina em questão, os conselheiros municipais apresentaram as principais funçôes do Conselho Municipal da Juventude de Blumenau, realizaram dinâmica com o intuito de perceber qual era a visão dos jovens sobre si e como eles percebiam o olhar do Estado, da família e da sociedade para com a juventude. Também, esclareceram sobre as açôes do Conselho na cidade e suas demandas em prol dos jovens. Esse encontro permitiu aos estudantes conhecerem e compreenderem a importância da atuação do conselho na arena municipal, bem como reconhecer a existência de instituiçôes compostas e direcionadas para a juventude.

Já a sexta e sétima oficinas foram organizadas com o intuito de planejar e elaborar a produção de vídeos que tratassem sobre o que trabalhamos ao longo das oficinas cotemplando o olhar dos jovens. Os bolsistas de extensão organizaram junto aos grupos o roteiro para elaboração dos vídeos. O objetivo dessa atividade consistiu na possibilidade dos jovens expressarem suas reflexóes e ideias que consideraram mais relevantes no âmbito do projeto. $\mathrm{O}$ resultado evidenciou a preocupação com o respeito à diversidade, em especial de gênero; com o direito à educação e às condições físicas e administrativas da escola; a liberdade de expressão em contraponto com o período ditatorial também foi temática de destaque. Desse modo, os vídeos receberam os seguintes títulos: vídeo 1: Liberdade, vídeo 2: Direitos Humanos, vídeo 3: Livres 
\& Iguais, vídeo 4: Direitos Humanos e vídeo 5: Direitos Humanos e a escola.

Os vídeos finalizados foram tema de apreciação no Seminário Juventude, Direitos Humanos e Inclusão Social, no qual se promoveu a integração e o diálogo entre os membros do projeto, os acadêmicos da Universidade Regional de Blumenau e a comunidade externa. Nesse evento, também foi realizada uma roda de conversa intitulada "A Juventude do Estatuto: (in)definiçôes e representaçóes", na qual se debateu os direitos da juventude e o processo de elaboração e aprovação do Estatuto da Juventude. O debate contemplou aspectos trabalhados com os jovens na escola, mas também problematizou tanto o papel da juventude e sua complexidade quanto a importância dos direitos dos jovens na sociedade brasileira, tendo em vista a diversidade e a desigualdade vigentes no país.

$\mathrm{Na}$ oitava e última oficina, realizamos uma avaliação com os jovens sobre o projeto de extensão "Juventude, Direitos Humanos e Inclusão Social”, a partir da qual se estabelecerá novas estratégias de ação e oficinas para os jovens.

Em síntese, é importante frisar, que a juventude representa muito mais que somente números ou estatísticas, os jovens são a expressão mais concreta da sociedade e, por isso, precisamos saber ouvir o que eles têm a nos dizer, valorizando sua diversidade na sociedade brasileira.

\section{CONSIDERAÇÕES FINAIS}

Trazer o tema da Juventude e Direitos Humanos para o projeto de extensão possibilitou evidenciar que é cada vez mais forte na contemporaneidade debater e refletir sobre os mitos que ainda hoje envolvem tais questóes. Nesse sentido, em tempos (neo) conservadores, possibilitar aos jovens um olhar diferente sobre os Direitos Humanos - desmistificando os jargóes como "bandido bom é bandido morto" - foi de extrema relevância e riqueza, tendo em vista o enfrentamento das distorçôes postas nos discursos sobre os Direitos Humanos. Além disso, evidenciar o tema da Juventude e da participação da juventude na sociedade brasileira é compreender que esse processo é recente e ainda deixa lacunas nos espaços que o Estado e a própria sociedade 
civil oferecem para esse diálogo.

Atualmente, dentre as temáticas relevantes na extensão universitária encontram-se também o reconhecimento da juventude e das suas especificidades em relação a crianças e adultos. Em diferentes espaços, como no meio acadêmico ou nas mídias, bem como nas agendas governamentais e não governamentais, os jovens têm angariado visibilidade. Nos meios de comunicação, por exemplo, os jovens aparecem ora vítimas da violência, ora protagonistas de problemas sociais, desemprego, drogas, gravidez precoce, dentre outros (NOVAES, 2007).

Como anteriormente referido, no Brasil, as discussóes acerca dos direitos da juventude ocorreram principalmente a partir de 2003, contudo o reconhecimento do jovem como sujeito de direitos ocorreu somente em 2010 com a aprovação da PEC da Juventude. Esse documento reconhece os jovens nas suas especificidades, facilitando a elaboração de políticas públicas e programas destinados especialmente à juventude. Entretanto, os princípios e diretrizes dessas políticas destinadas aos jovens atualmente baseiam-se no Estatuto da Juventude, através da Lei no 12.852 (BRASIL, 2013).

A valorização dos Direitos Humanos e a divulgação do Estatuto da Juventude são fundamentais para os jovens, uma vez que lhes proporciona mecanismos para agir e criticar sua realidade. Durante a execuçáo do projeto foi inegável a importância das oficinas, com destaque para a surpreendente e ativa participaçáo dos/as jovens estudantes, pois desde o início se mostraram interessados, dispostos e com enorme capacidade expressiva. Desse modo, verifica-se a relevância do projeto, uma vez que as discussóes proporcionadas nas oficinas demonstraram o engajamento dos estudantes nas temáticas propostas. Paralelamente, percebe-se que o espaço para debates sobre os Direitos Humanos é profícuo e necessário no âmbito escolar. Ainda que as diversas disciplinas escolares contemplem aspectos relacionados ao tema, a relação estabelecida com os jovens e as suas reflexóes sinalizaram o entusiasmo por discutir a respeito de algumas questóes específicas, tais como o respeito pela diversidade e a importância de se conhecer os Direitos Humanos.

Faz-se necessário ainda destacar com maior ênfase a elaboração dos vídeos pelos estudantes, que trouxeram no seu olhar curioso às diversas 
percepçóes de mundo em relaçáo ao ser jovem nessa sociedade e a relaçáo direta com o conteúdo das oficinas ministradas ao longo da execução do projeto. Os vídeos indicam um processo de reflexão crítica desses jovens, tendo em vista que eles exploraram todos os temas trabalhados, como, por exemplo, o respeito, diversidade, gênero e liberdade.

Nesse sentido, o projeto atua promovendo diálogos entre os jovens, visando um pensamento crítico sobre os Direitos Humanos e da juventude, além de promover debates com os profissionais responsáveis da área, para que mudanças e melhoras possam ser realizadas e para que o Estado observe de forma mais atenta a juventude.

Por fim, conhecer os jovens e participar um pouco de suas vidas nos fez aprender e repensar mais sobre os trabalhos a serem desenvolvidos com esse grupo, permitindo o encontro com a prática de uma realidade tão presente nas escolas públicas.

\section{REFERÊNCIAS}

ALVES, A. Pensar os jovens dos novos movimentos de juventude: contribuiçóes teóricas à construção de uma categoria. In: MACHADO, O. L. (Org.). Juventudes, democracia, direitos humanos e cidadania. Frutal: Prospectiva, 2013. p. 144-206.

BRASIL. Lei no 12.852, de 5 de agosto de 2013. Institui o Estatuto da Juventude e dispóe sobre os direitos dos jovens, os princípios e diretrizes das políticas públicas de juventude e o Sistema Nacional de Juventude - SINAJUVE. Disponível em: <http://www.planalto. gov.br/ccivil_03/_Ato2011-2014/2013/Lei/L12852.htm>. Acesso em: 22 mar. 2018.

CAVALCANTE, C. V. Caderno de artigos: infâncias, adolescências, juventudes e diretrizes das políticas públicas de juventude e o Sistema Nacional de Juventude - SINAJUVE. Goiânia: Gráfica e Editora América, 2014. 96 p.

MONDAINI, M. Direitos humanos e as lutas da juventude. In: MACHADO, Otávio Luiz (Org.). Juventudes, democracia, direitos humanos e cidadania. Frutal: Prospectiva, 2013. p. 8-20. 
. Direitos humanos. In: PINSKY, Carla Bassanezi (Org.). Novos temas em sala de aula. São Paulo: Editora Contexto, 2009. p. $55-72$.

MORAES, K. Juventude e gênero: um estudo com professores e estudantes da EEB. Prof. João Widemann. 2013. Trabalho de Conclusão de Curso (Graduação em Serviço Social) - Universidade Regional de Blumenau, Blumenau, 2013.

NOGUEIRA, Q. W. C. Esporte, desigualdade, juventude e participação. Revista Brasileira de Ciência Esporte, Porto Alegre, v. 33, n. 1, p. 103-117, 2011. doi: http://dx.doi.org/10.1590/S010132892011000100007 .

NOVAES, R. R. Políticas de juventude no Brasil: continuidades e rupturas. In: SEVERO, M. F. S. W. O Estatuto de Juventude no Brasil (2004-2013). Relaçôes de poder, disputas por hegemonia e Direitos humanos. Jundiaí: Paco Editorial, 2015. p. 253-280.

. Encontro de pesquisadores e pesquisadoras de políticas juventude. Brasília: Presidência da República, 2014. 538 p.

SILVA, A. M. M. Direitos humanos na educaçáo básica: qual o significado? In: SILVA, A. M. M.; TAVARES, C. (Org.). Políticas e fundamentos da educaçáo em direitos humanos. São Paulo: Cortez, 2010. p. 41-63.

ZENAIDE, M. de N. T. Os desafios da educação em direitos humanos no ensino superior. In: SILVA, A. M. M.; TAVARES, C. (Org.). Políticas e fundamentos da educaçáo em direitos humanos. São Paulo: Cortez, 2010. p. 64-83.

Submetido em 2 de maio de 2018.

Aprovado em 19 de julho de 2018. 